\title{
An Enhanced Power Generation Centre for More Electric Aircraft Applications
}

\author{
Xiaoyu Lang, Tao Yang, Hossein Balaghi Enalou, Serhiy Bozhko, Pat Wheeler \\ Power Electronics, Machines and Control Group \\ The University of Nottingham \\ Nottingham, UK \\ Xiaoyu.Lang@nottingham.ac.uk, eezsb1@exmail.nottingham.ac.uk
}

\begin{abstract}
The more-electric aircraft (MEA) concept has become a major trend due to its multiple advantages. Many functions which are conventionally driven by pneumatic, hydraulic and mechanical power systems are replaced by electrical ones onboard MEA. This results in increased electrical power demand for MEA. Due to power off-take limit from high-pressure (HP) spool of an engine, extra power needs to be extracted from the low-pressure (LP) spool. Besides, recent studies have revealed that transferring power between LP and HP shafts in certain flight missions, like taxiing and descending will not only decrease fuel consumption but also increase compressor surge margins. This paper introduces an enhanced power generation centre for the MEA applications. It extracts power from both HP and LP spools, with each shaft is driving one electrical generator. These generators supply electrical power to a common DC bus through active AC/DC converters. Using the droop-control concept, the power sharing between LP and HP shafts can be smoothly controlled. Control method when power transferred from LP spool to HP spool is also presented. This architecture is built and simulated in the Matlab/Simulink environment. Simulations results including performances of electrical machines, power converters and engine under different scenarios are presented in this paper.
\end{abstract}

Keywords-Modeling, power transfer, more electric aircraft (MEA), engine operating mode, starter/generator control.

\section{INTRODUCTION}

During the past decades, great progress has been made towards more electric aircraft (MEA) due to advantages like reduced $\mathrm{CO}_{2}$ and $\mathrm{NO}_{\mathrm{x}}$ emission, decreased fuel consumption, low maintenance cost and etc. [1-3]. Due to the increased electrical equipment onboard MEA, it is essential to extract more electrical power from aircraft engines. This leads to significant challenges to design an efficient and reliable electrical power system (EPS) [4]. Different EPS structures are studied and compared in [5]. It reveals that compared with AC system generally adopted in modern aircrafts, the HVDC system is superior due to its high efficiency, convenience of paralleling DC multiple buses, no need for reactive power compensation [6-7]. Therefore, HVDC serves as a better choice for EPS structure.

Besides the challenge in EPS design, the increased electrical power demand also requires a suitable power extraction system in the engine. Conventionally, electrical power is extracted from the HP spool only [1]. However, extracting power only from HP spool could have a negative impact on the performance of engine, like compressor surge [15]. In [8-9], it has been proved that there is a limit on the

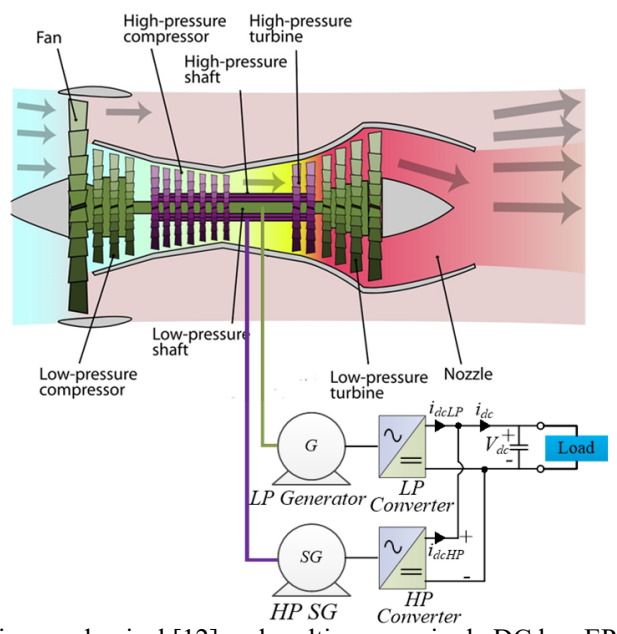

Fig.1 Engine mechanical [12] and multi-source single DC bus EPGC.

amount of power off-take from HP shaft. If the power extracted is over the limit, the engine will surge and stall. This issue can be addressed either by increasing the speed of HP shaft or bypass excess air to fan discharge duct, whereas those measurements will increase the fuel consumption and lead to fuel waste [10]. Another way to extract more power is to take power from LP shaft, and this will lead to a multi-source power generation system within the engine.

A promising EPS with multi-source supplying a main DC bus is shown in Fig.1, and it will be referred as enhanced power generation centre (EPGC) in this paper. The engine fan, the LP compressor (LPC), and the LP turbine are connected through LP shaft. The HP compressor (HPC) and the HP turbine are connected via HP shaft. A starter/generator (SG) is attached to HP spool and a generator is linked to LP spool. The two electric machines are regulated by two bidirectional converters and supply a common main DC bus, of which the nominal voltage is $270 \mathrm{~V}$ according to standard MIL-STD-704F. Here two permanent magnet machines (PMMs) are adopted. Details about why choosing PMMs can be found in [11]. The typical loads in MEA are constant impedance load (CIL), like resistive loads; And constant power load (CPL), like motor drives regulated by power converters. It also worth to note that such parallel generation system is able to provide "no-break" power even one of the generator shutdown.

In addition to the aforementioned advantages, the EPGC can also achieve power transfer between LP and HP shafts, which would be beneficial for engine performance. For example, when engine operates at low speed settings, like 


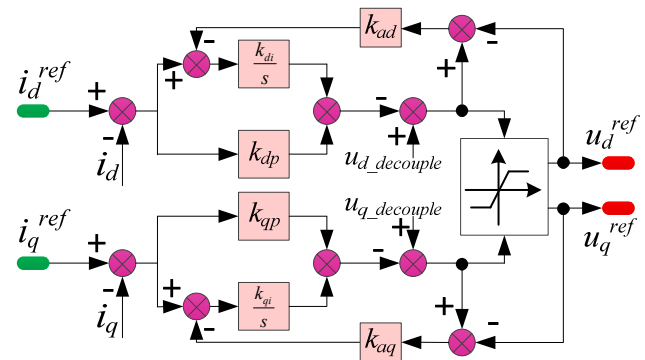

Fig.2 $d q$-axes current controller with anti-windup and decoupling terms.

taxiing and descent, the speed of HPC decreases which means HPC accepts less airflow. Thereby the bleeding is implemented between LPC and HPC to bypass excess air to fan discharge duct, preventing the risk of LPC surge. However, this action creates the waste of thrust. While by adopting the EPGC in Fig.1, some power of LP shaft can be transferred to HP shaft by controlling HP SG in motoring mode to speed up the HP shaft. This will not only improve fuel efficiency, but also increase compressor surge margin.

This paper introduces a concept of enhanced power generation centre and the power transfer control between different sources within the centre. In Section II, the mathematic modelling of essential elements within the power generation centre and related control design are introduced. In Section III, the power generation centre is tested through simulations, and the engine performances are also incorporated. Section IV concludes the whole paper.

\section{System Modeling ANd Control Method Design}

\section{A. $d q$ axes Current Controller Design}

Within the EPGC, it is assumed that PMMs are used for both HP and LP power generation channel. The mathematic model of PMMs electrical machine in generator mode has been widely introduced in literatures and is given as:

$$
\left\{\begin{array}{l}
\frac{d i_{d}}{d t}=\frac{1}{L_{d}}\left(-u_{d}-R i_{d}+\omega_{e} L_{q} i_{q}\right) \\
\frac{d i_{q}}{d t}=\frac{1}{L_{q}}\left(-u_{q}-R i_{q}-\omega_{e} L_{d} i_{d}+\omega_{e} \psi_{f}\right)
\end{array}\right.
$$

where $u_{d}$ and $u_{q}$ are stator voltages in $d$ and $q$ axes respectively; $i_{d}$ and $i_{q}$ are stator currents in $d$ and $q$ axes respectively; $L_{d}$ and $L_{q}$ are stator inductance in $d$ and $q$ axes respectively; $R$ is the stator resistance; $\psi_{f}$ is the flux linkage of permanent magnet; $\omega_{e}$ represents electrical speed. For a surface-mounted PMM, $L_{d}=L_{q}=L_{s}$.

The current controller design for both HP power generation channel and LP power generation channel are with the same structure as shown Fig.2. The design process of control parameters can refer to [13], which is briefly presented below:

$$
\begin{aligned}
k_{d p}=k_{q p} & =2 \zeta \omega_{n} L_{s}-R & & k_{d i}=k_{q i}=\omega_{n}^{2} L_{s} \\
k_{a d} & =k_{d i} / k_{d p} & & k_{a q}=k_{q i} / k_{q p}
\end{aligned}
$$

where $\omega_{n}$ is the desired closed-loop bandwidth of current-loop, $\zeta$ is the damping ratio. Here $\omega_{n}$ is set as 9420 $\mathrm{rad} / \mathrm{s}(1.5 \mathrm{kHz})$, and $\zeta$ chosen as 0.707 , then the proportion,

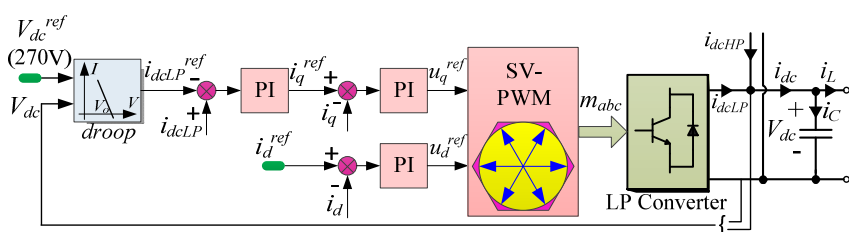

Fig.3 The control block diagram of LP power generation channel.

integration and anti-windup parameters can be obtained.

\section{B. Flux Weakening Controller Design}

Since HP machine works in a very high speed (e.g. from $10,000 \mathrm{r} / \mathrm{min}$ to $20,000 \mathrm{r} / \mathrm{min}$ [1]), flux weakening is needed to guarantee the HP machine to operate within the voltage limit circle. The command of $d$ axis current can be shown:

$$
i_{d}{ }^{r e f}=\frac{k_{F W}}{s}\left(u_{c}{ }^{\max }-u_{c}\right)
$$

where $k_{F W}$ is the integration gain of flux weakening controller; $u_{c}^{\max }=V_{d c} / \sqrt{3}, u_{c}=\sqrt{\left(u_{d}^{\text {ref }}\right)^{2}+\left(u_{q}^{\text {ref }}\right)^{2}}$.

\section{LP Channel Voltage Controller Design}

Fist consider the design process for LP power generation channel. The overall control diagram of LP power generation channel is shown in Fig.3. The HP power generation is with the same control structure. The HP and LP power generation channels are in parallel and supplying a common DC bus. Power sharing between two channels are achieved by droop control. A current-mode droop method presented in [14] is adopted in this paper due to its advantages, including the absence of communication, high modularity, and immunity from the impact of cable impedance. The power sharing is achieved by supplying the total load current $i_{d c}$ with currents $i_{d c L P}$ and $i_{d c H P}$, and $i_{d c}=i_{d c L P}+i_{d c H P}$. Using droop control characteristic, the references for $i_{d c L P}$ and $i_{d c H P}$ can be given:

$$
i_{d c L P}{ }^{r e f}=\frac{V_{d c}{ }^{r e f}-V_{d c}}{g_{L P}} \quad i_{d c H P}{ }^{r e f}=\frac{V_{d c}^{r e f}-V_{d c}}{g_{H P}}
$$

where $g_{L P}$ and $g_{H P}$ are the droop gains and the current-mode droop characteristic is demonstrated in Fig.3.

In the following session the modelling process for LP power generation channel will be presented. According to the electrical dynamics shown in (1), the $q$-axis voltage in Laplace form can be expressed as:

$$
u_{q}=-\left(R+L_{s} s\right) i_{q}+\omega_{e} \psi_{f}-\omega_{e} L_{s} i_{d}
$$

Since the generator is driven by an engine shaft which is normally with big inertia, the time constant of mechanical system will be bigger than that of electrical system. For small signal analysis, the electrical angular speed $\omega_{e}$, which is proportionate to the engine shaft speed can be viewed as a constant value. The small signal model of (5) thus can be given as:

$$
\Delta u_{q}=-\left(R+L_{s} s\right) \Delta i_{q}-\omega_{e} L_{s} \Delta i_{d}
$$

Considering the active power delivered by the LP generator as $P_{L P}$ :

$$
P_{L P}=\frac{3}{2}\left(u_{d} i_{d}+u_{q} i_{q}\right)
$$




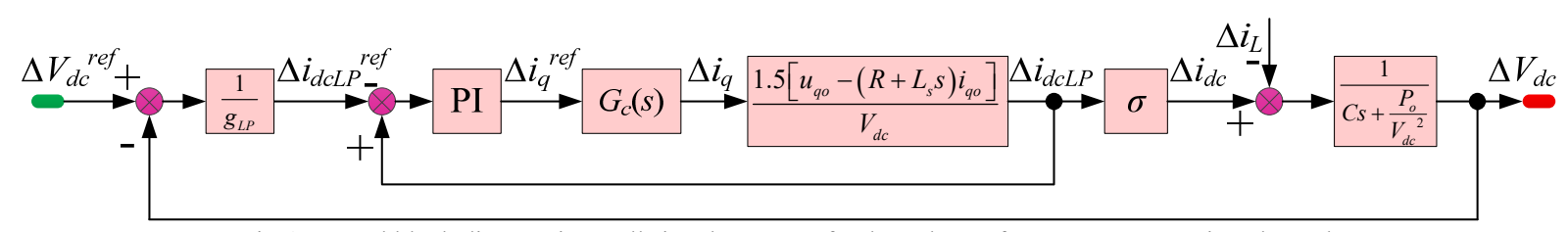

Fig.4 Control block diagram in small signal manner of voltage loop of LP power generation channel.

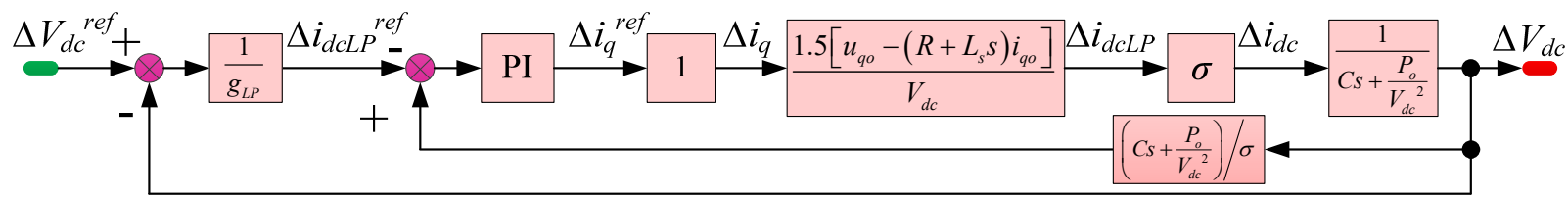

Fig.5 Transformed control block diagram in small signal manner of voltage loop of LP power generation channel.

Equation (7) can be linearized at operating point (indicated with the subscript "o") as:

$$
\Delta P_{L P}=\frac{3}{2}\left(\Delta u_{d} i_{d o}+u_{d o} \Delta i_{d}+\Delta u_{q} i_{q o}+u_{q o} \Delta i_{q}\right)
$$

Considering the situation that LP generator operates in a region that no flux weakening is required, i.e. $i_{d o}=0$ and $\Delta i_{d}=0$. Then (8) can be rewritten as:

$$
\Delta P_{L P}=\frac{3}{2}\left(\Delta u_{q} i_{q o}+u_{q o} \Delta i_{q}\right)
$$

Combining (9) and (6), the active power of LP generator in small signal manner can be written as:

$$
\Delta P_{L P}=\frac{3}{2}\left[u_{q o}-\left(R+L_{s} s\right) i_{q o}\right] \Delta i_{q}
$$

The active power delivered from the AC side to the DC side can also be calculated as:

$$
P_{L P}=V_{d c} i_{d c L P}
$$

Applying small signal analysis to (11) gives:

$$
\Delta P_{L P}=V_{d c o} \Delta i_{d c L P}+i_{d c L P o} \Delta V_{d c}
$$

Combining (12) and (10) gives the relation between $\Delta i_{d c L P}$ and $\Delta i_{q}$ :

$$
\frac{\Delta i_{d c L P}}{\Delta i_{q}}=\frac{1.5\left[u_{q o}-\left(R+L_{s} s\right) i_{q o}\right]}{V_{d c o}}-\frac{i_{d c L P o} \Delta V_{d c}}{V_{d c o} \Delta i_{q}}
$$

Generally, the dynamic response of outer voltage loop is slower than that of inner current loop. Hence, the term $\frac{i_{d c L P o} \Delta V_{d c}}{V_{d c o} \Delta i_{q}}$ can be treated as disturbance. Considering $i_{d c}=P / V_{d c}$, where $P$ is the total power required from the load, the following relationship in small signal manner can be derived according to the DC side configuration shown in Fig.3:

$$
C \frac{d \Delta V_{d c}}{d t}=\Delta i_{d c}-\Delta i_{L}=\left(\frac{\Delta P}{V_{d c o}}-\frac{P_{o}}{V_{d c o}^{2}} \Delta V_{d c}\right)-\Delta i_{L}
$$

In the Laplace domain, (14) can be rewritten as:

$$
\Delta V_{d c}=\frac{1}{C s+\frac{P_{o}}{V_{d c o}^{2}}}\left(\Delta i_{d c}-\Delta i_{L}\right)
$$

Assuming the power sharing ratio between LP converter and HP converter is $k: 1$, the ratio of corresponding droop gains should be $1: k$ according to (4). Then the following relationship can be obtained:

$$
i_{d c L P}=k i_{d c H P} \Rightarrow i_{d c}=\left(1+\frac{1}{k}\right) i_{d c L P}=\sigma i_{d c L P}
$$

where $\sigma=(k+1) / k$.

Using equations (13), (15) and (16), the control block diagram of voltage-loop can be obtained in Fig.4. It worth to note that in the generation mode, the active power flow is towards the DC link, which indicates that $i_{q}$ ref should be inversed for redirecting the power flow to the DC link [11]. This is the reason why $\Delta i_{d c L P}$ ref is negative in Fig.4.

In this paper, the bandwidth for voltage-loop is designed as $200 \mathrm{~Hz}$. Therefore, the current-loop can be simplified as a unit module since the bandwidth of current-loop is set to $1.5 \mathrm{kHz}$, i.e. $G_{c}(s) \approx 1$. Considering $\Delta \underline{i}_{L}$ as a disturbance, and moving the feedback junction from $\Delta i_{d c L P}$ to $\Delta V_{d c}$, the diagram can be converted into Fig.5. Using the zero of PI controller to eliminate the pole of forward path, the PI controller can be designed using:

$$
\frac{k_{v p} s+k_{v i}}{s}=\frac{\gamma_{L P}\left(C s+P_{o} / V_{d c}^{2}\right)}{s}
$$

where $k_{v p}$ and $k_{v i}$ are the proportion and integration gains of PI controller, $\gamma_{L P}$ is a factor related to closed-loop bandwidth. (17) reveals that $k_{v p}$ and $k_{v i}$ are adaptive according to specific operation conditions, like output power $P$ and DC voltage $V_{d c}$. This will guarantee the desired transient and steady performance of DC voltage loop.

The machine parameter is shown in Table I, where $R=0.02 \Omega, L_{s}=99 \mu \mathrm{H}$. And $V_{d c o}=270 \mathrm{~V}, C=1.5 \mathrm{mF}$. Assuming the speed of LP generator is $4,000 \mathrm{r} / \mathrm{min}$ at full thrust setting, then $u_{q o} \approx \omega_{e} \psi_{f}=45.8 \mathrm{~V}$. The selection of droop gain $g_{L P}$ is $1 / 5$. In this paper, HP converter and LP converter are assumed to be with the same topology and switching devices, thereby assume they account for same power, i.e. $\sigma=2$. The $V_{d c}$ closed-loop bode diagram when total power $P$ changes from $20 \mathrm{~kW}$ to $60 \mathrm{~kW}$ is shown as Fig.6 when $\gamma_{L P}$ is tuned to 600 .

It can be seen from Fig. 6 that in the low-frequency region the magnitude is smaller than 0 . This can be explained by the feature of droop control: the actual DC link voltage is smaller than the reference in heavy load condition due to the 


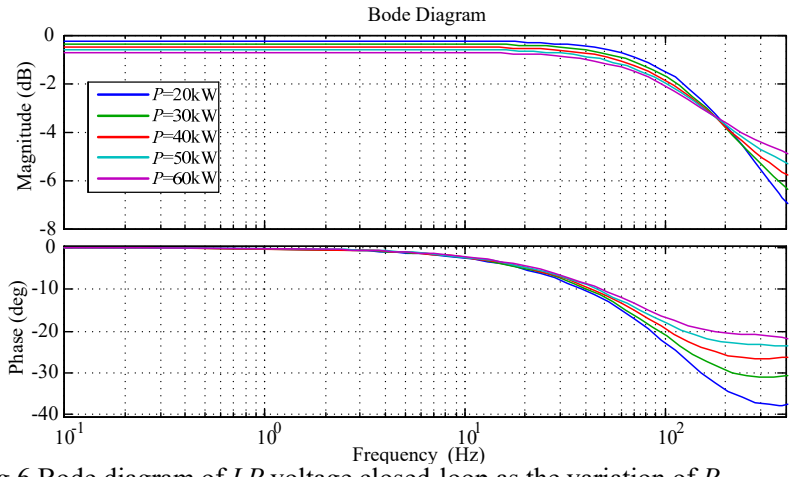

Fig.6 Bode diagram of $L P$ voltage closed-loop as the variation of $P$.

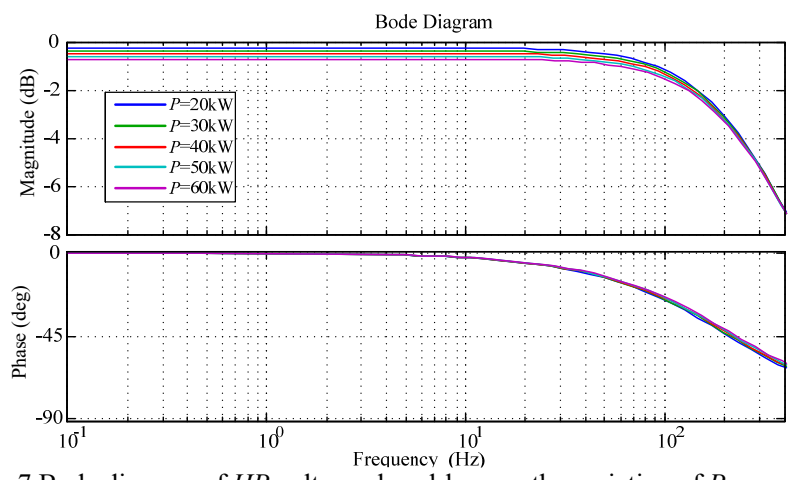

Fig.7 Bode diagram of $H P$ voltage closed-loop as the variation of $P$.

droop effect. Moreover, at $200 \mathrm{~Hz}$ the magnitude damps $-3 \mathrm{~dB}$ compared with the starting value in low frequency region. This indicates that the bandwidth of designed LP DC voltage closed-loop is around $200 \mathrm{~Hz}$ no matter how $P$ changes.

\section{HP Channel Voltage Controller Design}

For the controller design for HP power generation channel, it is slightly different from the above process. Since HP machine works at a high speed, $i_{d}<0$ to guarantee the flux weakening operation. In this case, $i_{d}$ can be expressed using the following equation, which is also the expression of voltage limit circle:

$$
i_{d}=\frac{-\omega_{e} \psi_{f}+\sqrt{V_{\max }^{2}-\left(\omega_{e} L_{s} i_{q}\right)^{2}}}{\omega_{e} L_{s}}
$$

where $\omega_{e}$ is the electrical speed of HP SG; $V_{\max }$ is $V_{d c} / \sqrt{3}$.

Then the relationship between $\Delta i_{d}$ and $\Delta i_{q}$ can be derived:

$$
\Delta i_{d}=\frac{\partial f}{\partial i_{q}} \Delta i_{q}=-\frac{\omega_{e} L_{s} i_{q}}{\sqrt{V_{\max }{ }^{2}-\left(\omega_{e} L_{s} i_{q}\right)^{2}}} \Delta i_{q}
$$

Using equation (8) and (19), the transfer function between $\Delta i_{d c H P}$ and $\Delta i_{q}$ can be obtained:

$$
\frac{\Delta i_{d c H P}}{\Delta i_{q}}=\frac{-L_{s} i_{q o} s+\left(\omega_{e} L_{s}+u_{q o}+u_{d o} \frac{\partial f}{\partial i_{q}}-R i_{q o}\right)}{V_{d c}}
$$

The structure of DC voltage loop control block diagram of HP power generation channel is the same as that of LP channel which is shown in Fig.5. Therefore the DC voltage closed-loop bode diagram can be obtained and given in
TABLE I. PARAMETERS OF PMM

\begin{tabular}{cc}
\hline \hline Parameter & Rated value \\
\hline Motor Power & $45 \mathrm{~kW}$ \\
Poles & 6 \\
Phases & 3 \\
Stator Resistance & $0.02 \Omega$ \\
Stator Inductance (in $d q$ axes) & $99 \mu \mathrm{H}$ \\
Flux Linkage of Magnet & $0.03644 \mathrm{~Wb}$ \\
\hline \hline
\end{tabular}

Fig.7. In Fig.7, assuming the speed of HP generator is $25,000 \mathrm{r} / \mathrm{min}$ at full thrust settings. The droop gain $g_{H P}$ is set as $1 / 5$. The total power $P$ changes from $20 \mathrm{~kW}$ to $60 \mathrm{~kW}$. The factor $\gamma_{H P}$ which is related to bandwidth is tuned to 100 . From Fig.7 it can be concluded that the closed-loop bandwidth for HP voltage loop is around $200 \mathrm{~Hz}$ when choosing $\gamma_{H P}$ to 100 .

\section{E. Power Transfer Control Design}

The LP and HP spools of an engine are not mechanically connected, and they independently rotate [1]. In [15] it has been proved that transfer certain amount of power between two shafts could improve the engine performance at certain Engine Operating Mode. In this paper, power transfer from LP shaft to HP shaft is studied. The EPGC shown in Fig.1 is able to achieve power transfer between these two shafts by manipulating one of the converters as inverter and the machine in motoring mode. The control method is proposed in the following.

Assuming the rotary speed of HP machine as $\omega_{m}$, the mechanical power is $P_{m}=\omega_{m} T_{e}$, where $T_{e}$ is the torque of HP machine. $\omega_{m}$ is imposed by the engine shaft, therefore only torque, or current can be controlled when outputting certain power. The HP machine in this paper is also assumed to be a surface-mounted PMM of which the parameters are shown in Table I. The torque $T_{e}$ can be expressed as:

$$
T_{e}=1.5 p \psi_{f} i_{q H}
$$

where $i_{q H}$ is the $q$-axis current of HP SG

From (21), the $i_{q H}$ reference can be obtained:

$$
i_{q H}{ }^{r e f}=\frac{P_{H P}}{1.5 p \psi_{f} \omega_{m}}
$$

where $P_{H P}$ is the power transferred from LP to HP side.

From (22), the $i_{q H}{ }^{\text {ref }}$ can be obtained if $P_{H P}$ is fixed. And $i_{d H}{ }^{r e f}$ comes from flux weakening controller shown in part $B$. The current control structure of HP SG has already been presented in Fig.2. Therefore the power transfer from LP to HP shaft is realized by controlling $i_{d H}$ and $i_{q H}$.

However, it needs to note that during the power transfer process, the LP machine performs as the unique power source. On the one hand it provides power to HP machine, on the other hand feeds the main DC bus. Therefore, the droop control should be revised since there is no need for power sharing between multi-sources. Here a compensation term is used to compensate the voltage deviation caused by the droop control, and the new voltage reference is: 


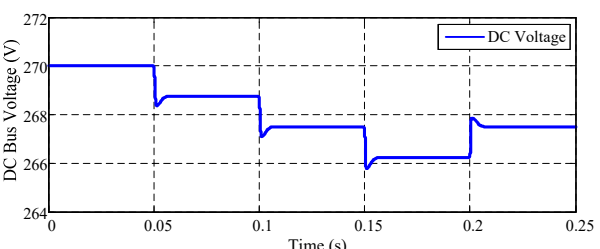

(a)

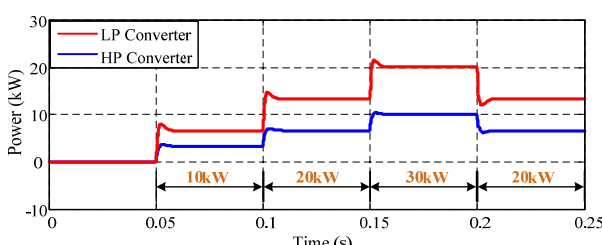

(b)

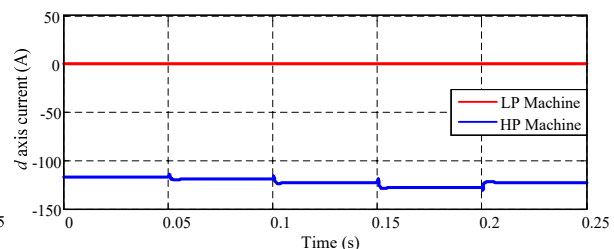

(c)

Fig.8 Simulation results in dual-generator mode: (a) DC bus voltage; (b) output power of LP and HP converters; (c) $d$-axis currents of LP and HP machines.

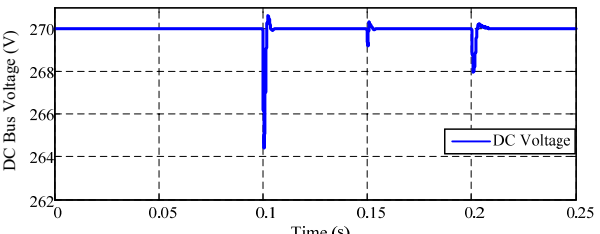

(a)

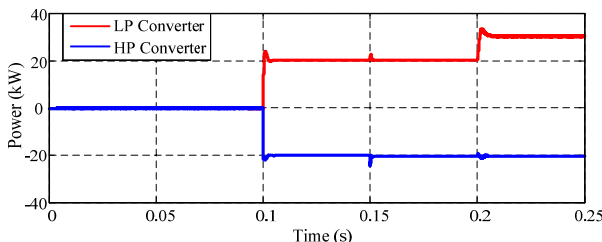

(b)

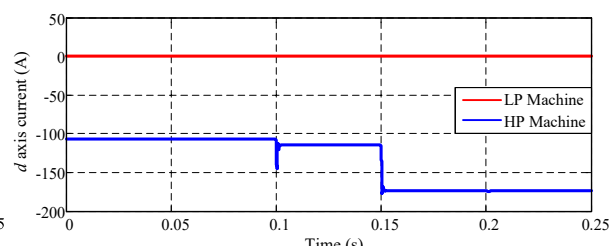

(c)

Fig.9 Simulation results in power-transfer mode: (a) DC bus voltage; (b) output power of LP and HP converters; (c) $d$-axis currents of LP and HP machines.

$$
V_{d c}{ }^{r e f}=270+i_{d c L P} g_{L P}
$$

Compared with the fixed voltage reference $270 \mathrm{~V}$ in Fig.3, the voltage reference is calculated from (23) when power is transferred from LP shaft to HP shaft. This will keep the DC bus voltage to $270 \mathrm{~V}$ in power transfer mode.

\section{Simulation Results}

In this section, simulations are conducted in the Matlab /Simulink environment. The main parameters of two PMMs are presented in Table I. More details about the design of machines can refer to the already published papers [16-17] of our research group. The voltage of main DC bus is set as $270 \mathrm{~V}$. HP and LP converters are selected as 3-phase, 2-level bidirectional converters. An inverter controlled PMM performs as a CPL which is connected to the main DC bus.

Simulation results are divided into three parts. In part $A$, the system operates in dual-generator mode, which means HP and LP machines both perform as generators. In part $B$, HP and LP machines operate in power-transfer mode, which means HP machine works in motor mode and LP machine remains as generator. In part $C$, the engine performance is studied when power is transferred from LP shaft to HP shaft.

\section{A. Simulation results in Dual-Generator Mode}

The simulative results when the system operates in dual generator mode are demonstrated in Fig.8. The speed of HP generator is $19000 \mathrm{r} / \mathrm{min}$ and that of LP generator is 4000r/min. The power sharing ratio between LP and HP converters is $2: 1$. The power demand of CPL at $0.05 \mathrm{~s}, 0.1 \mathrm{~s}$, $0.15 \mathrm{~s}, 0.2 \mathrm{~s}$ are $10 \mathrm{~kW}, 20 \mathrm{~kW}, 30 \mathrm{~kW}$, and $20 \mathrm{~kW}$, respectively. Fig.8(a) shows that as the power demand increases, the DC bus voltage will slightly drop due to droop effect. Fig.8(b) exhibits the output power of LP and HP converters. It can be seen that their power ratio keeps 2:1 during the whole process. Fig.8(c) shows the $d$-axis currents of LP and HP generators. Since the speed of LP generator is relatively slow, there is no need for flux weakening and its $d$-axis current remains 0 . While a negative $d$-axis current injects into HP generator for flux weakening operation. Moreover, as the increase of output power, the magnitude of $i_{d}$ will slightly increase. This can be explained by Fig.10, from which it can be seen that the magnitude of $i_{d}$ will increase as the

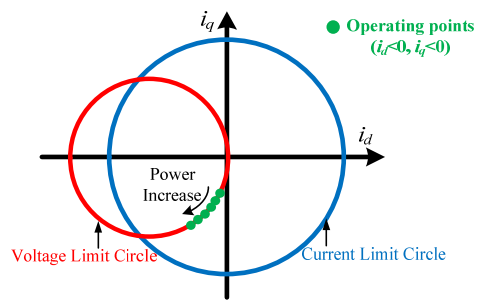

Fig.10 Voltage and current limit circles and operating point of HP machine.

operating points (the green dots) moving on the boundary of voltage limit circle.

\section{B. Simulation results in Power-Transfer Mode}

The simulative results when the system operates in power transfer mode are demonstrated in Fig.9. Before $0.1 \mathrm{~s}$, the system operates in dual-generator mode, machine speeds and power ratio configurations are same as that in part $A$. At $0.1 \mathrm{~s}$, the HP machine converts into motoring mode to speed up the HP shaft, and the power it demands is $20 \mathrm{~kW}$. At $0.15 \mathrm{~s}$, the speed of HP machine steps to $25,000 \mathrm{r} / \mathrm{min}$. At $0.2 \mathrm{~s}$, the CPL requires $10 \mathrm{~kW}$ from the DC bus.

Fig.9(a) shows that the DC bus voltage keeps $270 \mathrm{~V}$ during the whole process, which confirms the effectiveness of power transfer control method in Section II, D. Fig.9(b) exhibits the power of LP and HP converters. It can be seen at $0.1 \mathrm{~s}$ HP converter absorbs $20 \mathrm{~kW}$, which means $20 \mathrm{~kW}$ power is transferred from LP shaft to HP shaft. At $0.2 \mathrm{~s}$, LP converter power increase to $30 \mathrm{~kW}$ to balance the load demand. Fig.9(c) shows the $d$-axis currents of LP and HP machines. As that in dual-generator mode, the $d$-axis current of LP machine remains 0 . While a negative $d$-axis current injects into HP machine and its magnitude increases when the speed of HP machine steps at $0.15 \mathrm{~s}$.

\section{Engine Performance}

As aforementioned, transferring power from LP spool to HP spool at low speed settings could benefit both fuel efficiency and compressor surge margin. More detailed analysis could refer to [15]. In order to prove the benefits, maps from GASTURB (GasTurb 11, 2010) has been used to establish a two-spool high bypass ratio $(\mathrm{BPR}=8)$ unmixed flow $140 \mathrm{kN}$ turbofan engine, where LPT drives the fan and the LPC via LP shaft, HPT drives axial HPC and radial HPC. 


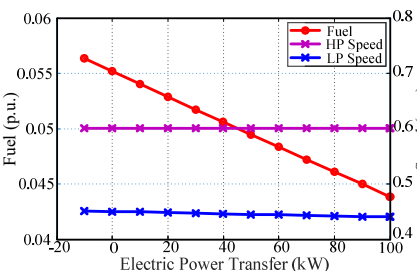

(a)

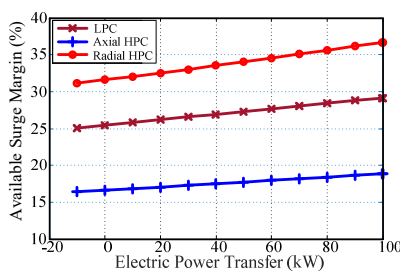

(b)
Fig.11 Engine behaviors in power transfer mode at flight idle mode, 20,000ft. (a) Fuel consumption and shaft speeds. (b) Surge margins of compressors.

In the process of descending, the engine is normally on an idle mode. Under this condition, the HP speed should not be lower than the minimum limitation otherwise the engine cannot sustain its speed anymore. Results for flight idle at 20,000ft are presented in Fig.11. The results reflect that as the increase of power transferred from LP to HP shaft, the speed of LP shaft will slight decrease and that of HP shaft will increase. This will reduce the fuel consumption and increase available compressors surge margin.

\section{CONCLUSION}

In this paper, a multi-source single DC bus enhanced power generation centre (EPGC) is studied for MEA application. The EPGC system can work in two modes: dual-generator and power-transfer modes. Generally, the two electrical machines both work as generators to supply a common DC bus. While at certain engine operation mode, like flight idle mode, some amount of power can be transferred from LP shaft to HP shaft by controlling HP machine to work as a motor to speed up the HP shaft. This will benefit the fuel efficiency and compressor surge margin. Control method design are presented for both dual-generator and power- transfer modes.

Simulation results show that in dual-generator mode, the two generators can supply power to DC bus, and the power sharing ratio is set by droop control gains. The DC bus voltage will slightly reduce as the increase of load power due to droop effect. While in power-transfer mode, the LP machine serves as the only generator to supply power for both HP machine and load connected to the DC bus. And the DC bus voltage can be kept to its nominal value in steady state. In addition, the simulation results of engine performances confirm the improvement of fuel efficiency and compressor surge margin in flight idle mode if power transfer is carried out from LP to HP shaft. The results highlight the promising future for applying such EPGC system in future MEA applications.

\section{ACKNOWLEDGMENT}

This project has received funding from the Clean Sky 2 Joint Undertaking under the European Union's Horizon 2020 research and innovation program under grant agreement No 807081. The author Xiaoyu Lang also thanks the funding from China Scholarship Council (CSC).

\section{REFERENCES}

[1] B. Sarlioglu and C. T. Morris, "More electric aircraft: Review, challenges, and opportunities for commercial transport aircraft," IEEE Trans. Transport. Electrific., vol. 1, no. 1, pp. 54-64, Jun. 2015.
[2] J. S. Ngoua Teu Magambo et al., "Planar Magnetic Components in More Electric Aircraft: Review of Technology and Key Parameters for DC-DC Power Electronic Converter," IEEE Trans. Transport. Electrific., vol. 3, no. 4, pp. 831-842, Dec. 2017.

[3] P. W. Wheeler, J. Clare, A. Trentin, and S. Bozhko, "An Overview of the More Electrical Aircraft," Proceedings of the Institution of Mechanical Engineers, Part G: Journal of Aerospace Engineering, vol. 227, pp. 578-585, 2013.

[4] J. A. Rosero, J. A. Ortega, E. Aldabas, and L. Romeral, "Moving towards a more electric aircraft," IEEE Aerosp. Electron. Syst. Mag., vol. 22, no. 3, pp. 3-9, Mar. 2007.

[5] P. Wheeler and S. Bozhko, "The more electric aircraft: Technology and challenges," IEEE Electrific. Mag., vol. 2, no. 4, pp. 6-12, 2014.

[6] X. Liu, P. Wang, and P. C. Loh, "A hybrid AC/DC microgrid and its coordination control," IEEE Trans. Smart Grid, vol. 2, no. 2, pp. 278-286, Jun. 2011.

[7] H. Kakigano, Y. Miura, and T. Ise, "Low-voltage bipolar-type dc microgrid for super high quality distribution," IEEE Trans. Power Electron., vol. 25, no. 12, pp. 3066-3075, Dec. 2010.

[8] H. B. Enalou, M. Rashed, P. Kulsangcharoen, C. I. Hill and S. Bozhko, "Nonlinear aircraft engine model for future integrated power center development," in Proc. Electrical Systems for Aircraft, Railway, Ship Propulsion and Road Vehicles Int. Transportation Electrification Conf. (ESARS-ITEC), 2016, pp. 1-5.

[9] E. Astfalk, "Konzepterstellung einer Generator Management Unit für ein Unmanned Aerial Vehicle," Diplom Thesis, University of Federal Defence Munich, 2009.

[10] G. C. Lemmers, Jr. and D.S. Behling, "High to low pressure spool summing gearbox for accessory power extraction and electric start," U.S. Patent 7882 691, Feb. 8, 2011.

[11] Yeoh, Seang Shen. Control strategies for the More Electric Aircraft starter-generator electrical power system. Diss. University of Nottingham, 2016.

[12] https://en.wikipedia.org/wiki/Turbofan.

[13] R. Burgos, P. Kshirsagar, A. Lidozzi, F. Wang, and D. Boroyevich, "Mathematical model and control design for sensorless vector control of permanent magnet synchronous machines," in Proc. IEEE Workshops COMPEL, Jul. 2006, pp. 76-82.

[14] F. Gao, S. Bozhko, G. Asher, P. Wheeler, and C. Patel, "An improvedvoltage compensation approach in a droop-controlled DC power system for the more electric aircraft," IEEE Trans. Power Electron., vol. 31, no. 10, pp. 7369-7383, Oct. 2016.

[15] H. B. Enalou et al, "A Preliminary Study into Turbofan Performance with LP-HP Power Exchange, " Global Power and Propulsion Forum, 2018, to be published.

[16] W. Fernando, P. Arumugam, C. Gerada, "Design of a Stator for a High-Speed Turbo-generator with Fixed Permanent Magnet Rotor Radius and Volt-Ampere Constraints," IEEE Trans. Energy Convers.

[17] W. Fernando, P. Arumugam and C. Gerada, "Volt-ampere constrains and its influence on inductance limits in high speed PM machine design," 8th IET International Conference on Power Electronics, Machines and Drives (PEMD 2016), Glasgow, 2016, pp. 1-6. 